Check for updates

Cite this: RSC Adv., 2018, 8, 32664

\title{
Synthesis of $\alpha, \beta$-unsaturated esters of perfluoropolyalkylethers (PFPAEs) based on hexafluoropropylene oxide units for photopolymerization $\uparrow$
}

\author{
Céline Bonneaud, (DD ${ }^{\mathrm{b}}$ Mélanie Decostanzi, ${ }^{\mathrm{b}}$ Julia Burgess, ${ }^{\mathrm{a}}$ Giuseppe Trusiano, ${ }^{\mathrm{c}}$ \\ Trevor Burgess, ${ }^{a}$ Roberta Bongiovanni, (D) Christine Joly-Duhamel ${ }^{b}$ \\ and Chadron M. Friesen (D)*a
}

\begin{abstract}
$\alpha, \beta$-unsaturated esters are usually synthesized for polymer applications. However, the addition of maleate (cis-configuration) to a fluorinated moiety is challenging due to its potential isomerization during esterification. Various synthetic routes were attempted and led to very low conversion or side-products. The immiscibility of both reagents combined with an easy isomerization or attack on the double bond were potential explanations. In this paper, the synthesis of maleates oligo(hexafluoropropylene oxide) is reported by Steglich esterification and the reaction conditions are discussed depending on the molecular weight of the fluorinated moieties. After UV-curing, hydrophobic polymers were obtained by copolymerization with vinyl ethers by electron acceptor-donor systems.
\end{abstract}

Received 28th July 2018

Accepted 6th September 2018

DOI: $10.1039 / \mathrm{c} 8 \mathrm{ra0} 0354 \mathrm{k}$

rsc.li/rsc-advances

\section{Introduction}

$\alpha, \beta$-unsaturated esters are very useful in polymer applications. ${ }^{1-3}$ Two configurations of $\alpha, \beta$-unsaturated esters are conceivable: the cis-configuration (maleate) and the transconfiguration (fumarate) (Fig. 1). In this paper, we focused on the mechanism and synthesis of maleates containing fluorinated moieties. Indeed, the synthesis of the corresponding fumarates can then easily be transposed but the maleates are inclined towards isomerization and consequently their synthesis is more challenging. In the past, maleate monomers have been successfully copolymerized with a variety of monomers such as vinyl acetate, ${ }^{1,4,5}$ vinyl ether, ${ }^{2}$ epoxy ${ }^{3}$ or even hydrophobic types. ${ }^{6}$ They have been seen in applications such as latex films, ${ }^{1,5}$ polyelectrolytes ${ }^{6}$ or cooperative complexation of cyclodextrins. ${ }^{7}$ It is also well known that photopolymerization is a fast and eco-friendly process; using UV-light at room temperature with maleates contributes to this environmentally

\footnotetext{
${ }^{a}$ Trinity Western University, Department of Chemistry, 7600 Glover Road, Langley, British Columbia V2Y 1Y1, Canada. E-mail: chad.friesen@twu.ca

${ }^{b}$ Ingénierie et Architectures Macromoléculaires, Institut Charles Gerhardt, Ecole Nationale Supérieure de Chimie de Montpellier (UMR5253-CNRS), 240 Avenue Prof Emile Jeanbrau, 34296 Montpellier Cedex 5, France

${ }^{\circ}$ Department of Applied Science and Technology, Politecnico di Torino, 10128 Torino, Italy

$\dagger$ Electronic supplementary information (ESI) available: Copies of ${ }^{1} \mathrm{H},{ }^{13} \mathrm{C}, \mathrm{IR}$, GC-MS spectra for compounds 1a-f, $2 \mathbf{a}-\mathbf{f}, \mathbf{3 a}-\mathbf{b}, \mathbf{4 a},{ }^{19} \mathrm{~F}$, TGA, DSC spectra for 2a-f, 3a-b, 4a and MALDI-TOF for 2a-f. IR spectra for the kinetics of photopolymerization. See DOI: 10.1039/c8ra06354k
}

friendly chemical process. The copolymerization of vinyl ethers with maleates was accomplished under UV-light by electron acceptor-donor (AD) systems. These systems proved to form an alternated copolymer by utilizing $[\mathrm{AD}]$ properties and had the appropriate stoichiometric ratios. ${ }^{8,9}$ Under UV-curing, maleates usually showed a faster reactivity than the more thermodynamically stable fumarates. ${ }^{2}$ Nonetheless, the opposite effect was observed ${ }^{10}$ and another study will be dedicated to the comparison of their kinetics. In comparison to the common (meth)acrylic systems, their polymerization is less sensitive to oxygen. ${ }^{11,12}$ The use of $\alpha, \beta$-unsaturated esters with fluorinated chains is almost absent from the literature. ${ }^{13-15}$ However, novel outstanding properties such as high hydrophobicity and oleophobicity can be obtained thanks to the fluorine atoms. The aim of our work was to bond monoalkyl maleates to long fluorinated moieties. Perfluoropolyalkylethers (PFPAEs) are non-toxic fluorinated long chains ${ }^{16}$ which demonstrate interesting properties in many high technology areas such as aerospace, aeronautic (seals, gaskets) or automotive industries. ${ }^{17}$

These PFPAEs based on structural units such as $-\left(\mathrm{CF}_{2} \mathrm{O}\right)-$, $-\left(\mathrm{CF}_{2} \mathrm{CF}_{2} \mathrm{O}\right)-,-\left(\mathrm{CF}_{2} \mathrm{CF}_{2} \mathrm{CF}_{2} \mathrm{O}\right)-$ and $-\left(\mathrm{CF}\left(\mathrm{CF}_{3}\right) \mathrm{CF}_{2} \mathrm{O}\right)-$ showed high chemical and thermal inertness, low surface energy and flammability, and excellent ageing and weather resistances. ${ }^{18}$ Oligo(hexafluoropropylene) (oligo(HFPO)) products obtained by the anionic ring-opening reaction of hexafluoropropylene oxide with cesium fluoride were used in this work. Two different molecular weights of oligo(HFPO) were studied $\left(M_{\mathrm{w}} \sim 1250 \mathrm{~g}\right.$ $\mathrm{mol}^{-1}$ and $M_{\mathrm{w}} \sim 2000 \mathrm{~g} \mathrm{~mol}^{-1}$ ). Due to the high withdrawing effect of the fluorine atoms on its long chain, the nucleophilicity 
of these oligomers is particularly low. They also inherently have the characteristic of being insoluble in many organic solvents and are only soluble in specific fluorinated solvents. Conversely, the highly polar maleates are soluble in many organic solvent types but are insoluble in fluorinated solvents. After the synthesis of the monoalkyl maleates with different substituents was achieved, different synthetic methods were conceivable and are discussed for the esterification of the fluorinated alcohols to the remaining carboxylic acid group of the maleate. After their synthesis, the photopolymerization was carried out to create highly hydrophobic polymers.

\section{Experimental}

\section{Materials}

Maleic anhydride, methanol, ethanol, propan-2-ol, pentanol, benzyl alcohol, phenol, tert-butyl alcohol, tert-amyl alcohol, thionyl chloride, triethylamine, carbonyldiimidazole, Amberlyst-15 hydrogen form (strongly acidic, cation exchanger, dry), dicyclohexylcarbodiimide, 4-dimethylamino pyridine, 2hydroxy-2-methylpropiophenone and dichloromethane were purchased from Sigma Aldrich. Triethylamine and thionyl chloride were distilled before use. Triethylamine and trifluorotoluene were kept under activated molecular sieves (3A). The different alcohols were previously dried by using $\mathrm{MgSO}_{4}$. 1,1,1,3,3-pentafluorobutane was purchased from Alfa Aesar. The $1250 \mathrm{~g} \mathrm{~mol}^{-1}$ oligo(HFPO) methylene alcohol was prepared from Krytox ${ }^{\circledR}$ acyl fluoride. The 1250 Krytox ${ }^{\circledR}$ acyl fluoride and the $2000 \mathrm{~g} \mathrm{~mol}^{-1}$ Krytox® methylene alcohol were kindly provided by E. I. du Pont de Nemours and Company.

\section{Analysis}

Fourier-transform (FT) - real time infrared spectroscopy (RTIR). Real-time infrared spectroscopy and photopolymerization kinetics were performed on a Nicolet Nexus apparatus by using OMNIC software. The UV light came from an OmniCure S2000 (Mercury lamp) equipment and the light output was controlled by OmniCure R2000 Radiometer. The real intensity provided to the sample was found to be $1 \mathrm{~mW} \mathrm{~cm} \mathrm{~cm}^{-2}$ thanks to a radiometer from Solatell. The product was dropped
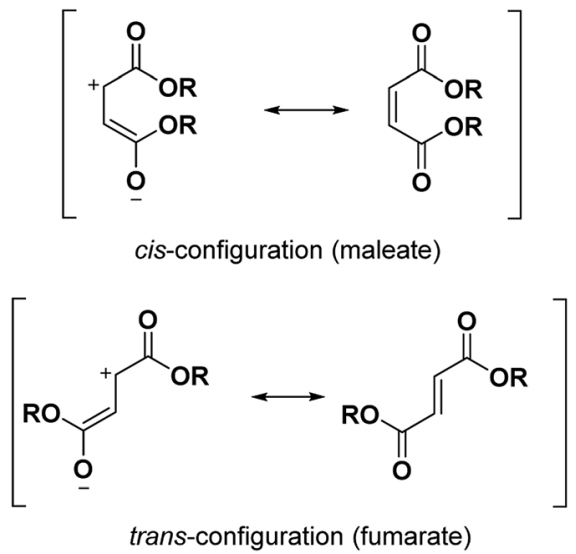

Fig. 1 Cis- and trans-configurations of $\alpha, \beta$-unsaturated esters. by using a pipette and a polypropylene film $(6 \mu \mathrm{m})$ was used as air protector. The sample was irradiated during 600 s. 2Hydroxy-2-methylpropriophenone was added as photoinitiator $(4 \% \mathrm{w} / \mathrm{w})$. The following of the kinetics was made by following the disappearance of the band at $1622 \mathrm{~cm}^{-1}$ for the vinyl ether. The calculated conversion rates were made based on the average of four repeats for the same experiment. The calculations were made by using the univariate method and confirmed by the peak deconvolution method. Some photopolymerization experiments were also performed on an UV production curing unit Fusion UV and LC6B Bench-top Conveyor equipped with a microwave lamp (linear power output of $1200 \mathrm{~W} \mathrm{~cm}^{-2}$ ). The sample was placed on a conveyor and passed repeatedly under the UV lamp at a speed of travel belt of $1 \mathrm{~m} \mathrm{~min}^{-1}$.

Gas chromatography (GC) mass spectrometry (MS). An Agilent Technologies 6890N GC was coupled with an Agilent Technologies 7638B series injector and Agilent Technologies 5975B inert mass spectrometer (MSD) was employed with electron impact (EI) as the mode of ionization. The GC was equipped with a Zebron ZB-5ms column, $30 \mathrm{~m} \times 0.18 \mathrm{~mm}$ internal diameter (ID), $0.18 \mu \mathrm{m}$ film thickness $\left(d_{\mathrm{f}}\right)$. The detector and the injector temperatures were $200{ }^{\circ} \mathrm{C}$ and $280{ }^{\circ} \mathrm{C}$, respectively. The temperature program started from $50^{\circ} \mathrm{C}$ with a $2 \mathrm{~min}$ hold then the heating rate was $25{ }^{\circ} \mathrm{C} \min ^{-1}$ until reaching $250{ }^{\circ} \mathrm{C}$ and holding at $250{ }^{\circ} \mathrm{C}$ for $2 \mathrm{~min}$. The total pressure 108

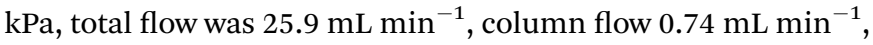
purge flow $3 \mathrm{~mL} \mathrm{~min}{ }^{-1}$, linear velocity $38.2 \mathrm{~cm} \mathrm{~s}^{-1}$, and a split injection of $30: 1$. The sample was previously diluted in methoxyperfluorobutane (3M's Novec ${ }^{\mathrm{TM}} \mathrm{HFE}-7100$ ) in a GC vial.

Nuclear Magnetic Resonance (NMR) spectroscopy. The structure of the products was determined by NMR spectroscopy at room temperature $\left(25^{\circ} \mathrm{C}\right)$ except if specified. NMR spectra were recorded on a Bruker AVANCE III $400 \mathrm{MHz}$ spectrometer instruments using $\mathrm{CDCl}_{3}$ and $\mathrm{C}_{6} \mathrm{D}_{6}$ capillaries as internal references for the oligo(HFPO) products. The experimental conditions were accomplished by using TopSpin 3.5 operating at $400.13\left({ }^{1} \mathrm{H}\right), 376.46\left({ }^{19} \mathrm{~F}\right), 100.62\left({ }^{13} \mathrm{C}\right) \mathrm{MHz}$. The letters s, d, t, q, quint, sext and spt stand for singlet, doublet, triplet, quartet, quintuplet, sextet and septuplet respectively.

Matrix assisted laser desorption ionization time-of-flight mass spectrometry (MALDI-TOF-MS). The homologue distributions of the products were determined with a Bruker AutoflexTM MALDI-TOF/TOF-MS spectrometer equipped with a 1 $\mathrm{kHz}$ smartbeam-II laser and reflector in positive ionization. For sample preparation, a 1 drop sample of oligo(HFPO) was added to a $1 \mathrm{~mL}$ solution of $50: 501 \% \mathrm{LiCl}$ in $\mathrm{MeOH}$ and $2 \%$ perfluorocinnamic acid dissolved in $50: 50$ $\mathrm{MeOH}$ : methoxynonafluorobutane (3 M HFE-7100). A $1 \mu \mathrm{L}$ solution was then pipetted on to a ground steel plate, dried, and irradiated for a minimum of 5000 shots.

Thermogravimetric analyses (TGA). The degradation temperatures were determined with a NETZSCH TG209F1 at a heating rate of $20^{\circ} \mathrm{C} \mathrm{min}{ }^{-1}$. Approximately $8 \mathrm{mg}$ of the sample were placed in an alumina crucible and heated from room temperature to $600{ }^{\circ} \mathrm{C}$ under inert atmosphere $\left(40 \mathrm{~mL} \mathrm{~min}^{-1}\right)$.

Differential scanning calorimetry (DSC). The glass transition temperatures were determined with a NETZSCH DSC200F3 
calorimeter. Constant calibration was performed using indium, $n$ octadecane and $n$-octane standards. $10-15 \mathrm{mg}$ were placed in pierced aluminium pans and the thermal properties were recorded between $-150{ }^{\circ} \mathrm{C}$ and $100{ }^{\circ} \mathrm{C}$ at $20{ }^{\circ} \mathrm{C} \mathrm{min}{ }^{-1}$. The glass transition temperatures were measured at the second heating ramp and are the onset values. Nitrogen was used as the purge gas.

Contact angle measurements. The hydrophobicity was determined thanks to a contact angle system OCA20 coupled with a CCD-camera from DataPhysics Instrument using the software SCA20 4.1. The measurements were made in air at room temperature by the sessile drop technique with distilled water. Three repeats were made on three different samples previously irradiated. Their difference in the average value was no more than $3^{\circ}$.

\section{Synthesis of the monoalkyl maleates}

In a general procedure, $10 \mathrm{mmol}$ of maleic anhydride $(981 \mathrm{mg})$ were dissolved in $20 \mathrm{mmol}$ of the corresponding alcohol (2 eq.). The mixture was stirred at room temperature or heated between $45{ }^{\circ} \mathrm{C}$ and $55^{\circ} \mathrm{C}$. The different reaction times and temperatures are reported for each compound. The alcohol was then removed under high vacuum or the product was purified by flash chromatography if specified.

Monomethyl maleate 1a (R.T., $5 \mathrm{~h}$, yield $=96 \%):{ }^{1} \mathrm{H}$ NMR $\left(400 \mathrm{MHz}, \mathrm{CDCl}_{3}, 25{ }^{\circ} \mathrm{C}, \delta\right): 3.90$ (s, CH3OCO, 3H), 6.43 (dd, $-\mathrm{CH}$ $=\mathrm{CHCOOH}-, 2 \mathrm{H},{ }^{3} \mathrm{~J}_{\mathrm{H}-\mathrm{H}}=12.7 \mathrm{~Hz}$ and $\left.35.2 \mathrm{~Hz}\right),{ }^{13} \mathrm{C} \mathrm{NMR}(100$ $\left.\mathrm{MHz}, \mathrm{CDCl}_{3}, 25{ }^{\circ} \mathrm{C}, \delta\right): 53.8\left(\mathrm{CH}_{3} \mathrm{OCO}-\right), 129.0(-\mathrm{CH}=$ $\mathrm{CHCOOH}-), 137.0$ (-CHCOOH), $164.3\left(\mathrm{CH}_{3} \mathrm{CH}_{2} \mathrm{OCO}-\right), 168.4$ (-COOH), GC-MS, 70 eV, m/z: 41.1 (17), 43.1 (34), 45 (34), 54 (24), 55 (10), 59 (11), 72 (17), 99 (100), 100 (16), FT-IR (ATR) $\nu_{\max }$ $\left(\mathrm{cm}^{-1}\right): 819.6,856.2,1165.6,1222.5,1439.6,1633.1,1727.90$.

\section{Synthesis of maleate oligo(HFPO) $M_{\mathrm{w}} \sim 2000 \mathrm{~g} \mathrm{~mol}^{-1}$}

To a solution of oligo(HFPO) alcohol $\left(M_{\mathrm{w}}=2000 \mathrm{~g} \mathrm{~mol}^{-1}, 2 \mathrm{~g}, 1\right.$ mmol), monoalkyl maleate (2 eq.) and DMAP (0.1 eq.) in 1,1,1,3,3-pentafluorobutane (15 mL), 2.2 eq. of DCC in DCM (10 $\mathrm{mL}$ ) were added dropwise at $0{ }^{\circ} \mathrm{C}$ during $30 \mathrm{~min}$. After $5 \mathrm{~min}$ of reaction, the ice bath was removed. The conversion of the reaction was followed by ${ }^{19} \mathrm{~F}$ NMR. After $20 \mathrm{~min}$, the reaction was stopped. The reaction mixture was filtrated and concentrated under vacuum. A flash column chromatography by solid deposit was performed. The solvents were removed under vacuum to afford oil products. The products were analyzed by NMR, GC-MS, MALDI-TOF and IR.

Methyl maleate oligo(HFPO) 2a (purified by flash chromatography $10: 90$ EtOAc : pentane, yield $=55 \%):{ }^{1} \mathrm{H}$ NMR (400 $\left.\mathrm{MHz}, \mathrm{C}_{6} \mathrm{D}_{6}, 25{ }^{\circ} \mathrm{C}, \delta\right): 3.63\left(\mathrm{~s},-\mathrm{COOCH}_{3}, 3 \mathrm{H}\right), 4.64-4.78$ (m, HFPO-CH2O-, 2H), 6.20 (dd, $-\mathrm{CH}=\mathrm{CH}-$ cis, $2 \mathrm{H},{ }^{3} \mathrm{~J}_{\mathrm{H}-\mathrm{H}}=11.9 \mathrm{~Hz}$ and $30.7 \mathrm{~Hz}),{ }^{13} \mathrm{C} \mathrm{NMR}\left(100 \mathrm{MHz}, \mathrm{C}_{6} \mathrm{D}_{6}, 25{ }^{\circ} \mathrm{C}, \delta\right): 50.7$ $\left(\mathrm{CH}_{3} \mathrm{OCO}-\right), 59.8\left(-\mathrm{COOCH}_{2} \mathrm{R}_{\mathrm{f}}\right), 127.5\left(-\mathrm{CH}=\mathrm{CHCOOCH}_{2}-\right)$, $131.2\left(-\mathrm{CHCOOCH}_{2} \mathrm{R}_{\mathrm{f}}\right), 163.1\left(-\mathrm{COOCH}_{3}\right), 164.6\left(\mathrm{R}_{\mathrm{f}} \mathrm{CH}_{2} \mathrm{COO}-\right)$, ${ }^{19} \mathrm{~F}$ NMR $\left(376 \mathrm{MHz}, \mathrm{C}_{6} \mathrm{D}_{6}, 25{ }^{\circ} \mathrm{C}, \delta\right):-135.2\left(\mathrm{~d}_{\mathrm{R}-\mathrm{s}} \mathrm{q},-\mathrm{CF}\left(\mathrm{CF}_{3}\right)\right.$ $\mathrm{CH}_{2} \mathrm{R}_{\mathrm{h}}$ ), GC-MS, $70 \mathrm{eV}, \mathrm{m} / z$ : 68.9 (55), 84.9 (14), 99.9 (16), 113 (100), 118.9 (14), 146.9 (17), 149.9 (26), 168.9 (73), MALDI-TOF, $[\mathrm{M}+\mathrm{Li}]^{+}:$1765.5, 1931.8, 2098.0, 2263.2, 2429.5, FT-IR (ATR) $\nu_{\max }\left(\mathrm{cm}^{-1}\right): 982.4,1126.4,1230.2,1646.0,1743.7$.

\section{Synthesis of maleate oligo(HFPO) $M_{\mathrm{w}} \sim 1250 \mathrm{~g} \mathrm{\textrm {mol } ^ { - 1 }}$}

To a solution of oligo(HFPO) alcohol $\left(M_{\mathrm{w}}=1250 \mathrm{~g} \mathrm{~mol}^{-1}\right.$, $938 \mathrm{mg}, 0.75 \mathrm{mmol})$, monoalkyl maleate (2 eq.) and DMAP (0.1 eq.) in 1,1,1,3,3-pentafluorobutane $(10 \mathrm{~mL})$ and DCM $(30 \mathrm{~mL})$, 2.2 eq. of DCC in DCM $(10 \mathrm{~mL})$ were added dropwise at $0{ }^{\circ} \mathrm{C}$ during $20 \mathrm{~min}$. After $5 \mathrm{~min}$ of reaction, the ice bath was removed. The conversion of the reaction was followed by ${ }^{19} \mathrm{~F}$ NMR. After $15 \mathrm{~min}$, the reaction was stopped. The reaction mixture was filtrated and concentrated under vacuum. After filtration onto silica and then onto Celite ${ }^{\circledR}$, the solvents were removed under vacuum to afford clear colorless oil products.

Methyl maleate oligo(HFPO) 3a (yield $=72 \%):{ }^{1} \mathrm{H}$ NMR $(400$ $\mathrm{MHz}, \mathrm{C}_{6} \mathrm{D}_{6}, 25^{\circ} \mathrm{C}, \delta$ ): 3.77 (s, -OCH3, 3H), 4.76-4.89 (m, HFPO$\mathrm{CH} 2 \mathrm{O}-, 2 \mathrm{H}$ ), 6.32 (dd, $-\mathrm{CH}=\mathrm{CH}-$ cis, $2 \mathrm{H},{ }^{3} \mathrm{~J}_{\mathrm{H}-\mathrm{H}}=11.9 \mathrm{~Hz}$ and $34.3 \mathrm{~Hz}$ ), $6.87\left(\mathrm{dd},-\mathrm{CH}=\mathrm{CH}\right.$-trans, $2 \mathrm{H},{ }^{3} \mathrm{~J}_{\mathrm{H}-\mathrm{H}}=15.9 \mathrm{~Hz}$ and $28.7 \mathrm{~Hz}, 4 \%),{ }^{13} \mathrm{C}$ NMR (100 MHz, $\left.\mathrm{C}_{6} \mathrm{D}_{6}, 25{ }^{\circ} \mathrm{C}, \delta\right): 51.0$ $\left(\mathrm{CH}_{3} \mathrm{OCO}-\right), 60.0\left(-\mathrm{COOCH}_{2} \mathrm{R}_{\mathrm{f}}\right), 127.5\left(-\mathrm{CH}=\mathrm{CHCOOCH}_{2}-\right)$, $131.5\left(-\mathrm{CHCOOCH}_{2} \mathrm{R}_{\mathrm{f}}\right), 163.3\left(-\mathrm{COOCH}_{3}\right), 165.0\left(\mathrm{R}_{\mathrm{f}} \mathrm{CH}_{2} \mathrm{COO}-\right)$, ${ }^{19} \mathrm{~F}$ NMR (376 MHz, $\left.\mathrm{C}_{6} \mathrm{D}_{6}, \delta\right):-135.3\left(\mathrm{~d}_{\mathrm{R}-\mathrm{s}} \mathrm{q},-\mathrm{CF}\left(\mathrm{CF}_{3}\right) \mathrm{CH}_{2} \mathrm{R}_{\mathrm{h}}\right)$, GC-MS, 70 eV, m/z: 69.1 (32), 85.1 (13), 99 (12), 100.1 (12), 113.1 (100), 150.1 (11), 169 (54), FT-IR (ATR) $\nu_{\max }\left(\mathrm{cm}^{-1}\right):$ 979.6, $1117.8,1226.6,1645.8,1742.3$.

\section{Synthesis of vinyl ether oligo(HFPO) $M_{\mathrm{w}} \sim 1250 \mathrm{~g} \mathrm{~mol}$}

To a solution of Krytox Acid Fluoride ( $2 \mathrm{~g}$ ) in $5 \mathrm{~mL}$ of previously dried trifluorotoluene with $363 \mu \mathrm{L}$ of dry triethylamine (1.5 eq.), $155 \mu \mathrm{L}$ of ethylene glycol vinyl ether ( 1 eq.) in $5 \mathrm{~mL}$ of dry trifluorotoluene was added dropwise at $0{ }^{\circ} \mathrm{C}$. After $5 \mathrm{~min}$, the ice bath was removed and the reaction mixture was left to stir at room temperature during $14 \mathrm{~h}$. The solvent and volatiles were removed under vacuum. The crude was then washed with water $(5 \times)$ and acetone $(3 \times)$. The solvent traces were then removed under vacuum.

4 (yield $=38 \%){ }^{1} \mathrm{H}$ NMR $\left(400 \mathrm{MHz}, \mathrm{C}_{6} \mathrm{D}_{6}, 25{ }^{\circ} \mathrm{C}, \delta\right): 3.86(\mathrm{br}$, $\left.-\mathrm{CH}_{2} \mathrm{CH} 2 \mathrm{OCH}=\mathrm{CH}_{\mathrm{a}} \mathrm{H}_{\mathrm{b}}, 2 \mathrm{H}\right), 3.94\left(\mathrm{dd},-\mathrm{CH}_{2} \mathrm{CH}_{2} \mathrm{OCH}=\right.$ $\mathrm{CH}_{\mathrm{a}} \mathrm{Hb}, 1 \mathrm{H},{ }^{3} \mathrm{~J}_{\mathrm{H}-\mathrm{H}}=6.7$ and $\left.2.1 \mathrm{~Hz}\right), 4.09\left(\mathrm{~d},-\mathrm{CH}_{2} \mathrm{CH}_{2} \mathrm{OCH}=\right.$ $\left.\mathrm{CHaH}_{\mathrm{b}}, 1 \mathrm{H},{ }^{3} \mathrm{~J}_{\mathrm{H}-\mathrm{H}}=14.5 \mathrm{~Hz}\right), 4.52\left(\mathrm{br},-\mathrm{CH} 2 \mathrm{CH}_{2} \mathrm{OCH}=\mathrm{CH}_{\mathrm{a}} \mathrm{H}_{\mathrm{b}}\right.$, 2H), 6.35 (dd, $-\mathrm{CH}_{2} \mathrm{CH}_{2} \mathrm{OCH}=\mathrm{CH}_{\mathrm{a}} \mathrm{H}_{\mathrm{b}}, 1 \mathrm{H},{ }^{3} \mathrm{~J}_{\mathrm{H}-\mathrm{H}}=6.7$ and 14.4 $\mathrm{Hz}),{ }^{13} \mathrm{C}$ NMR $\left(100 \mathrm{MHz}, \mathrm{C}_{6} \mathrm{D}_{6}, 25{ }^{\circ} \mathrm{C}, \delta\right): 64.0\left(-\mathrm{CH}_{2} \mathrm{CH}_{2} \mathrm{OCH}=\right.$ $\left.\mathrm{CH}_{2}\right),-65.9\left(-\mathrm{CH}_{2} \mathrm{CH}_{2} \mathrm{OCH}=\mathrm{CH}_{2}\right), 85.8\left(-\mathrm{CH}_{2} \mathrm{CH}_{2} \mathrm{OCH}=\right.$ $\left.\mathrm{CH}_{2}\right)$, $150.7\left(-\mathrm{CH}_{2} \mathrm{CH}_{2} \mathrm{OCH}=\mathrm{CH}_{2}\right), 158.6\left(-\mathrm{COOCH}_{2} \mathrm{CH}_{2} \mathrm{OCH}=\right.$ $\left.\mathrm{CH}_{2}\right),{ }^{19} \mathrm{~F}$ NMR $\left(376 \mathrm{MHz}, \mathrm{C}_{6} \mathrm{D}_{6}, 25{ }^{\circ} \mathrm{C}, \delta\right):-133.1\left(\mathrm{~d}_{\mathrm{R}-\mathrm{s}} \mathrm{q}\right.$, $-\mathrm{CF}\left(\mathrm{CF}_{3}\right) \mathrm{CH}_{2} \mathrm{R}_{\mathrm{h}}$ ), FT-IR (ATR) $\nu_{\max }\left(\mathrm{cm}^{-1}\right)$ : 979.1, 118.8, 1227.1, 1622.0, 1788.4 .

\section{Results and discussion}

\section{Synthesis of the starting monoalkyl maleates}

The different monoalkyl maleates were synthesized by the ringopening reaction of maleic anhydride with the corresponding alcohol. Poor-nucleophilic alcohols such as phenol, tertbutanol, tert-amyl alcohol did not permit the ring-opening reaction under mild conditions as expected. Indeed, the withdrawing mesomeric effect of the phenol or the high steric hindrance of the tert-butyl and tert-amyl explained their low nucleophilicity. Thus, benzyl alcohol was used as an alternative 


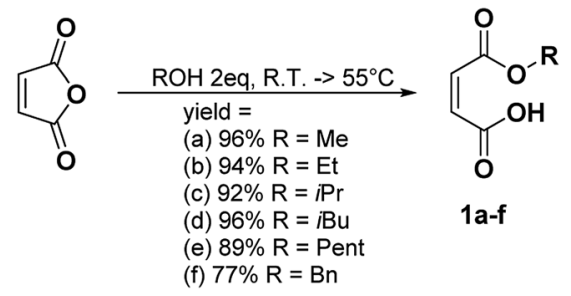

Scheme 1 Synthesis scheme of the monoalkyl maleates.

to create a hindered bulk on one side of the maleate. All the products were synthesized with a good yield (Scheme 1).

\section{Synthesis of the disubstituted maleates}

Four different synthetic strategies were attempted: by direct esterification, by using thionyl chloride, by using carbonyldiimidazole (CDI) and by Steglich esterification. No conversion or very low conversion was observed by direct esterification even in the presence of catalysts. Isomerization was highlighted by using thionyl chloride. In addition, the bonding of the in situformed imidazole into the double bond of the maleate by using CDI prohibited the use of any of these synthetic routes (See ESI $\dagger$ for further information).

\section{By Steglich esterification}

Carbonyldiimidazole is a "greener" method for esterification of the fluorinated alcohols to the maleates, but due to the nucleophilicity of the in situ-formed imidazole, a non-nucleophilic base, dicyclohexylcarbodiimide (DCC), was used with 4-dimethylaminopyridine (DMAP) as catalyst to carry out the Steglich esterification instead (Scheme 2).

In a common procedure, 2-4 equivalents of alcohol were used to achieve good yields. ${ }^{19}$ More recent procedures used only a slight excess of the carboxylic acid or the alcohol with a high efficiency of reactivity. ${ }^{\mathbf{2 0 - 2 2}}$ Before working on the long fluorinated oligo(HFPO) methylene alcohol, experiments were carried out on hydrogenated or partially fluorinated alcohols to determine if the desired product could be obtained. Different

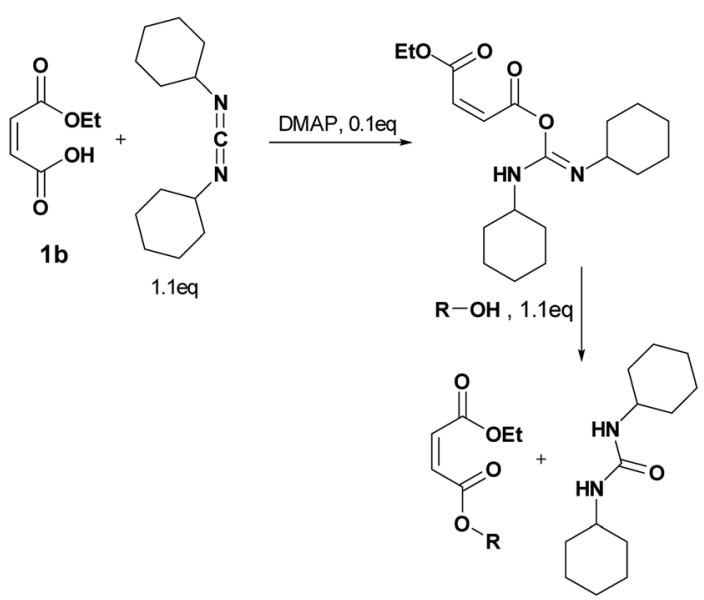

Scheme 2 Scheme synthesis of the esterification of maleate by Steglich esterification. alcohols were used as model molecules: methanol, 1-pentanol, 1-octanol and 2,2,3,3,4,4,5,5-octafluoro-1-pentanol. In any case, a complete conversion of the starting maleate was observed. However, side-products were also present (Table 1). The presence of the trans-product was reported in small quantity. Indeed, in the literature, it was reported for this maleate product a chemical shift for the two protons of the double bond of $6.24 \mathrm{ppm}^{23,24}$ whereas the chemical shift for the fumarate product was 6.85 ppm. ${ }^{24,25}$ As the cis and trans-products did not show the same reactivity in copolymerization,,$^{2,10}$ a control of the reaction time is essential.

A product from the addition of the alcohol onto the double bond was also observed. It was clearly identified thanks to the presence of three doublets of doublets at 2.43, 3.51 and $4.32 \mathrm{ppm}$. The three signals were correlated in ${ }^{1} \mathrm{H}-{ }^{1} \mathrm{H}$ COSY (as observed for the carbonyldiimidazole reaction). Nonetheless, the lower nucleophilicity of 2,2,3,3,4,4,5,5-octafluoro-1pentanol underwent a low percentage of this side-product (Fig. 2 \& Table 1). Three doublets of doublets were also observed at 2.85, 3.0 and $4.04 \mathrm{ppm}$ and were correlated in ${ }^{1} \mathrm{H}-{ }^{1} \mathrm{H}$ COSY. However, these signals did not correspond to the addition onto the $\alpha$-position of the acid as assumed at the beginning but to the formation of another side product: 1,3,5trisubstituted hydantoin. ${ }^{26,27}$ This product was prepared by an intramolecular reaction from the in situ activated carboxylic acid (I) due to the electrophilic centers of the double bond. Followed by a rearrangement called $\mathrm{O} \rightarrow \mathrm{N}$ acyl migration on (II), the corresponding 1,3,5-trisubstituted hydantoin (III) was formed (Scheme 3). It has to be noticed that the intramolecular reaction is always in competition with the nucleophilic substitution between the nucleophile $\left(\mathrm{ROH}, \mathrm{RNH}_{2}, \mathrm{RCOOH}\right.$, etc.) and the in situ activated carboxylic acid with DCC. By using $\alpha, \beta$ unsaturated carboxylic acids, the team of Volonterio et al. showed the synthesis of 1,3,5-trisubstituted hydantoins (III) by a one-pot domino condensation/aza-Michael addition/O $\rightarrow \mathrm{N}$ acyl migration of symmetric and asymmetric carbodiimides. Then a part of the alcohol did not react and remained in the final mixture. The hydantoin products were confirmed thanks to the three doublets of doublets as well as the triplets of triplets from the hydrogens of the cyclohexyl in $\alpha$-position of the amines (Fig. 2). As the nucleophilicty of 2,3,3,4,4,5,5-octafluoro-1pentanol is lower, more hydantoin product was formed. Concerning the octanol, the higher nucleophilicity allowed more formation of the desired product instead of hydantoin without a large amount of addition product to the $\alpha$-ester.

When the similar reaction was carried out in absence of any alcohol (Scheme 3), the 1,3,5-trisubstituted hydantoin was confirmed. Another product was found and the chemical shifts were typical of the diester maleate: one triplet from the $\mathrm{CH}_{3}-$, one quadruplet from the $-\mathrm{CH}_{2}-$ and one singlet from the hydrogen of the double bonds (See ESI $\dagger$ ). The assumed product was most likely the compound I, which was stable enough to be recovered. DMAP could also have attacked the carbonyl by following the Steglich mechanism (Scheme 3) and that would explain the low quantity of dicyclohexyl urea found. Besides, in presence of 1 equivalent of DMAP instead of using it as catalyst (0.1 eq.), no hydantoin was formed after $24 \mathrm{~h}$ and dicyclohexyl 
Table 1 Summary of the molar \% products generated from the Steglich esterifications reaction using (DCC/DMAP) ${ }^{a}$

\begin{tabular}{|c|c|c|c|c|c|}
\hline Product & Structure & $\begin{array}{l}\text { Methanol } \\
(\% \mathrm{~mol})\end{array}$ & $\begin{array}{l}\text { 1-pentanol } \\
(\% \mathrm{~mol})\end{array}$ & $\begin{array}{l}\text { 1-octanol } \\
\text { (\%mol) }\end{array}$ & $\begin{array}{l}2,2,3,3,4,4,5,5 \text {-octafluoropentanol } \\
(\% \mathrm{~mol})\end{array}$ \\
\hline Trans-product & & 8 & 4 & 6 & 4 \\
\hline $1,3,5$-Trisubstituted hydantoin & & 18 & 15 & 10 & 22 \\
\hline Addition on $\alpha$-ester & & 9 & 11 & 13 & 4 \\
\hline
\end{tabular}

urea was formed in larger quantities. Moreover, for the previous reactions, even if a slight excess (1.1 eq.) of the starting alcohol was used, a significant peak of this reagent was present at the end of the reaction in comparison to the complete conversion of the maleate. Furthermore, even by taking into account the percentage of non-used alcohol due to the hydantoin reaction, the percentage of alcohol was still higher than expected. By using 2 equivalents of maleate and DCC, the starting alcohol was fully consumed as well as the maleate. The use of 2 equivalents of maleate increased the conversion of the alcohol to the desired product. The conversion of the alcohol was also dependent on its nucleophilicity undergoing either the formation of hydantoin in presence of a poor nucleophilic alcohol or the formation of the $\alpha$-ester for a good nucleophile. In our case, oligo(HFPO) alcohol was not assumed to attack onto double bond due to the very low nucleophilicity of the long fluorinated chain. However, the 1,3,5-trisubstituted hydantoin is highly expected to be formed if our alcohol does not show fast enough reaction kinetics.

\section{Synthesis of maleate PFPAEs by steglich esterification}

Procedure in DCM. Based on the low nucleophilicity of the long fluorinated chain associated with a non-solubility in

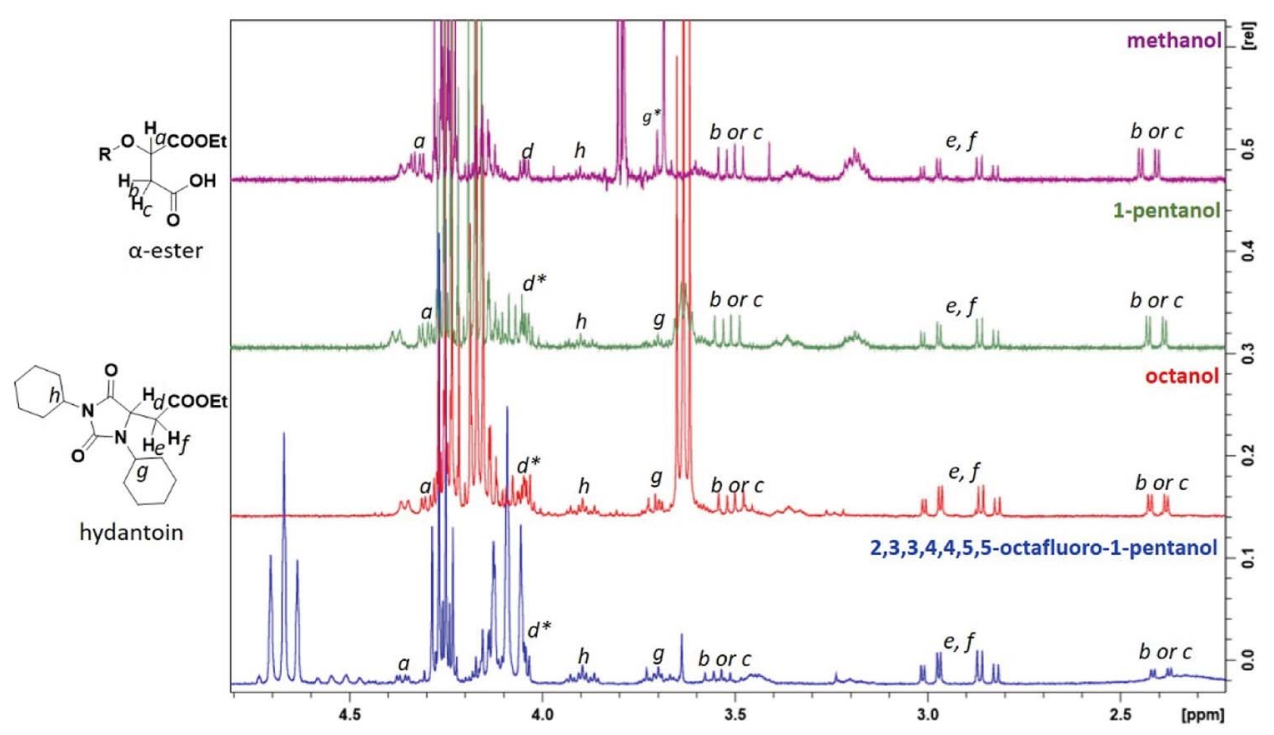

Fig. $2{ }^{1} \mathrm{H}$ NMR spectra of the side-products from Steglich esterification: (1) the addition onto the double bond of the maleate, (2) the formation of hydantoin (* signal overlapped). 


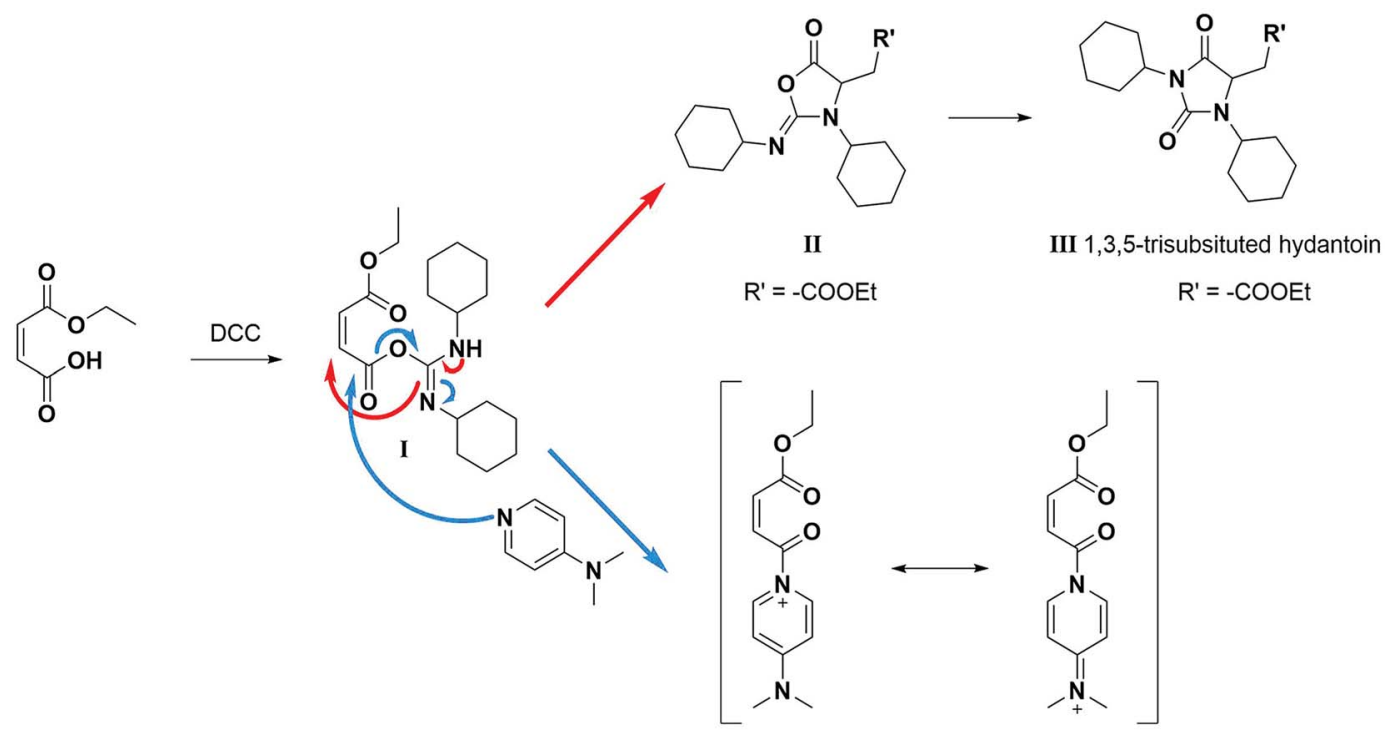

Scheme 3 Reaction scheme of the formation of hydantoin using DCC in absence of any nucleophilic reagent. ${ }^{26}$

dichloromethane (DCM), a slower conversion rate was expected. The correct cis-product was initially observed $\left({ }^{3} \mathrm{~J}_{\mathrm{H}-\mathrm{H}}=11.6 \mathrm{~Hz}\right)$. However, after $48 \mathrm{~h}$ of reaction, the trans-product appeared $\left({ }^{3} \mathrm{~J}_{\mathrm{H}-}\right.$ $\mathrm{H}_{\mathrm{H}}=15.5 \mathrm{~Hz}$ ) and an incomplete conversion was observed and confirmed by ${ }^{1} \mathrm{H}$ and ${ }^{19} \mathrm{~F}$ NMR (Scheme 4). Longer reaction times always led to higher percentage of isomerization as the trans-product is thermodynamically favorable.

Procedure in 1,1,1,3,3-pentafluorobutane:DCM mixture. In order to increase the solubility of oligo(HFPO) methylene alcohol, a mixture of solvents is a convenient procedure. However, depending on the molecular weight, the dilution as well as the mixture of solvents slightly differed. Combined with a use of excess of the monoalkyl maleate, DCC and DMAP, even if the hydantoin was formed, a faster reaction was assumed.

The first synthesis was carried out on the highest molecular weight $\left(M_{\mathrm{w}} \sim 2000 \mathrm{~g} \mathrm{~mol}^{-1}\right)$. This oligomer showed the lowest solubility in the organic solvent and was expected to show the lowest nucleophilicity. The procedure followed the Steglich esterification in Scheme 5 to synthesize six different maleates by using a mixture $60: 40$ 1,1,1,3,3-pentafluorobutane : DCM. The disappearance of the starting alcohol was followed by ${ }^{19} \mathrm{~F}$ NMR and confirmed in less than $20 \mathrm{~min}$. These oligo(HFPO) products have been purified by column chromatography for the first time. The purification mainly permitted the removal of any hydrogenated organic molecules such as the excess of DCC, starting monoalkyl maleate, DMAP, 1,3,5-trisubstituted hydantoin and the in situ formed dicyclohexyl urea. Thus, the

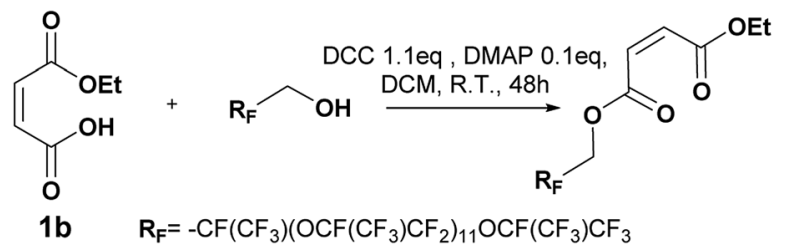

Scheme 4 Synthesis scheme of maleate oligo(HFPO) using DCC and DMAP. products could be analyzed by ${ }^{1} \mathrm{H},{ }^{13} \mathrm{C},{ }^{19} \mathrm{~F}$ NMR, GC-MS, FTIR and MALDI-TOF to confirm their structure. The doublet of doublet around 6.1-6.25 ppm with a ${ }^{3} \mathrm{~J}_{\mathrm{H}-\mathrm{H}}$ lower than $12 \mathrm{~Hz}$ confirmed the cis product. In addition, the maleate end group was supported by GC/MS with the correct fragments, by IR with the $\mathrm{C}=\mathrm{C}$ band at $1645 \mathrm{~cm}^{-1}$ as well as by MALDI-TOF thanks to the desired molecular weights $\left[\mathrm{M}+\mathrm{Li}^{+}\right.$. However, as they are not soluble in pentane and ethyl acetate except in high dilution it explains the low yields. Besides, a higher percentage of isomerization was detected for longer reaction times as well as a percentage of the starting alcohol. The reaction was then stopped as soon as the product was confirmed by ${ }^{19} \mathrm{~F}$ NMR.

On contrary to the longest chain, the oligo(HFPO) $\left(M_{\mathrm{w}} \sim\right.$ $1250 \mathrm{~g} \mathrm{~mol}^{-1}$ ) showed a highest percentage of the starting alcohol after purification. It was noticed that after $15 \mathrm{~min}$ of addition, no starting alcohol was observed. Overtime, a sidereaction caused a reversal of the reaction, leaving the starting alcohol. By using a higher dilution $\left(\left[\mathrm{C}_{M_{\mathrm{w}} \sim 1250 \mathrm{~g} \mathrm{~mol}^{-1}}\right]=0.02 \mathrm{~g}\right.$ $\mathrm{mL}^{-1}$ instead of $\left[\mathrm{C}_{\left.M_{\mathrm{w}} \sim 2000 \mathrm{~g} \mathrm{~mol}^{-1}\right]}=0.08 \mathrm{~g} \mathrm{~mL}^{-1}\right.$ ) and a mixture 20 : 80 1,1,1,3,3-pentafluorobutane : DCM, no starting alcohol was observed after $48 \mathrm{~h}$ (Scheme 6). However, for the same reaction stopped after $15 \mathrm{~min}$ (after confirmation by ${ }^{19} \mathrm{~F}$ NMR of absence of starting alcohol) and after column chromatography, $20 \%$ of the starting alcohol was observed. We believe the

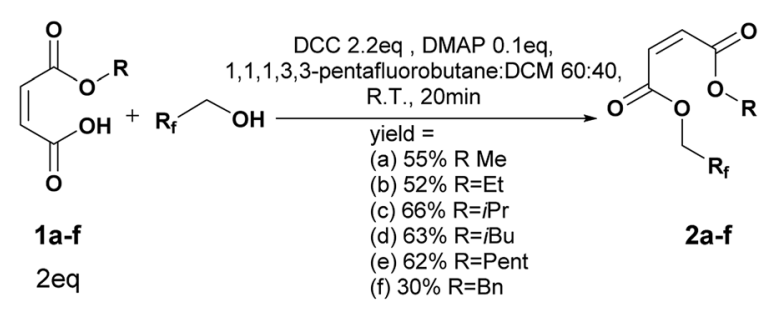

$\mathbf{R}_{\mathbf{F}}=-\mathrm{CF}\left(\mathrm{CF}_{3}\right)\left(\mathrm{OCF}\left(\mathrm{CF}_{3}\right) \mathrm{CF}_{2}\right)_{11} \mathrm{OCF}\left(\mathrm{CF}_{3}\right) \mathrm{CF}_{3}$

Scheme 5 Reaction scheme of Steglich esterification with oligo(HFPO) methylene alcohol $M_{\mathrm{w}} \sim 2000 \mathrm{~g} \mathrm{~mol}^{-1}$. 


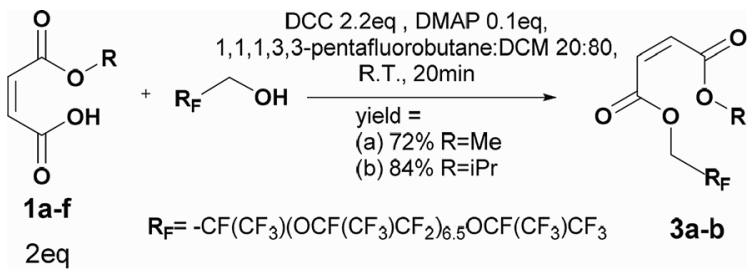

Scheme 6 Reaction scheme of Steglich esterification on oligo(HFPO) alcohol $M_{\mathrm{w}} \sim 1250 \mathrm{~g} \mathrm{~mol}^{-1}$.

product reverted back to the starting alcohol due to the $\mathrm{pH}$ and large excess of the silica. Besides, the longer fluorinated chained alcohol created higher steric hindrance, protecting itself from removal.

Photopolymerization of maleate and vinyl ether oligo(HFPO). Methyl maleate oligo(HFPO) (2a and 3a) were used in copolymerization with vinyl ether oligo(HFPO) 4 (Fig. 3) to form an electron acceptor-donor system. 2-Hydroxy-2methylpropiophenone was used as a photoinitiator (PI Fig. 3) due to its highly efficient homolytic scission under UVlight.

For a stoichiometric amount of maleate/vinyl ether with $4 \%$ $\mathrm{w} / \mathrm{w}$ of PI, a complete conversion of the vinyl ether was obtained in less than 40 s. (Fig. 4) No homopolymerization of 4 was observed under UV-light after $500 \mathrm{~s}$ and in presence of PI ( $4 \% \mathrm{w} /$ $\mathrm{w})$. The IR band $(\mathrm{C}=\mathrm{C})$ of the vinyl ether did not overlap with other structures, therefore, kinetics was done only on the vinyl ether band at $1622 \mathrm{~cm}^{-1}$. Surprisingly, in comparison with literature, a partial homopolymerization of 2a was observed in presence of PI but proved to be much slower than its copolymerization (See ESI $\dagger$ ). Besides, the vinyl ether 4 showed quantitative conversion and since a stoichiometric ratio was used, no homopolymerization of the maleate could have happened or only in small quantities within $40 \mathrm{~s}$. No clear effect was observed due to the chain length (2a and $\mathbf{3 a}$ ) for the polymerization kinetics. In absence of photoinitiator, no conversion of the monomers was observed. In addition, the presence of air was not a key factor in polymerization as the final conversion was reached in the same amount of time (See ESI $\dagger$ ). The degradation temperature $T_{5 \%}$ was mainly dependent on the chain length (i.e. $1250 \mathrm{~g} \mathrm{~mol}^{-1}$ and $2000 \mathrm{~g} \mathrm{~mol}^{-1}$ ). Concerning oligo(HFPO) with $M_{\mathrm{w}} \sim 1250 \mathrm{~g} \mathrm{~mol}^{-1}$, the addition of a substituent (maleates or vinyl ether) increased the degradation temperature in comparison to the starting alcohol. However, for the higher molecular weight, no changes were observed except for the benzyl maleate 2f due to the more stable phenyl group. The copolymers showed a similar $T_{5 \%}$ but demonstrated slower degradation kinetics than the monomers: $174{ }^{\circ} \mathrm{C}$ and $200{ }^{\circ} \mathrm{C}$ for $\mathbf{3 a}: \mathbf{4}$ and $2 \mathbf{a}: 4$ respectively. The glass transition temperatures were also linked

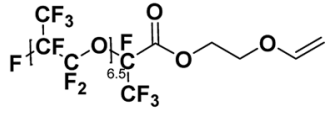

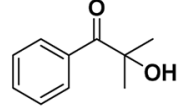

PI
Fig. 3 Structure of the vinyl ether oligo(HFPO) 4 and the photoinitiator PI.

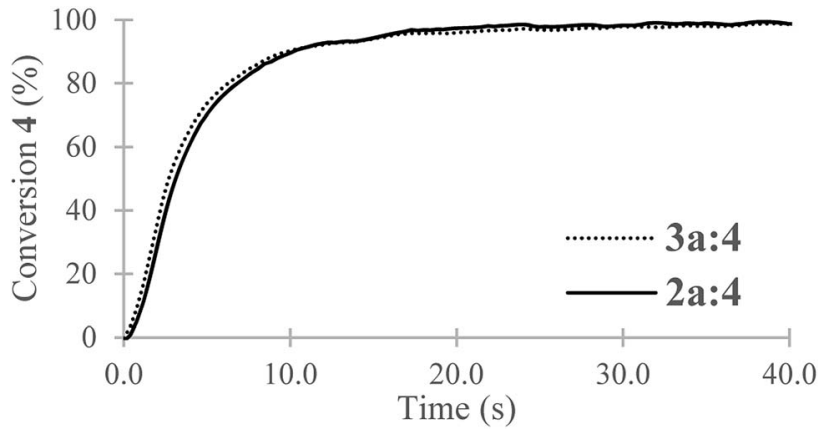

Fig. 4 Photopolymerization profiles of $3 a: 4$ and $2 a: 4$ in presence of photoinitiator $(4 \% \mathrm{w} / \mathrm{w})$.

with the length of the fluorinated chain: around $-75{ }^{\circ} \mathrm{C}$ and $-68{ }^{\circ} \mathrm{C}$, respectively for $1250 \mathrm{~g} \mathrm{~mol}^{-1}$ and $2000 \mathrm{~g} \mathrm{~mol}^{-1}$. Compound $2 \mathrm{f}$ showed a slightly higher $T_{\mathrm{g}}$ due to the reduced chain flexibility. Regarding the copolymers, only the glass transition temperature of the fluorinated phase was detected $\left(-69{ }^{\circ} \mathrm{C}\right.$ and $-68{ }^{\circ} \mathrm{C}$ for $3 \mathrm{a}: 4$ and $2 \mathrm{a}: 4$ respectively). Highly hydrophobic polymers (i.e. $109^{\circ}$ and $111^{\circ}$ for $3 \mathbf{a}: 4$ and $2 \mathrm{a}: 4$ respectively) were obtained, as reported for acrylic photopolymers containing PFPAEs' (see ESI $\dagger$ ). ${ }^{28,29}$

\section{Conclusions}

The synthesis of fluorinated maleates was successfully carried out by Steglich esterification. Indeed, the high reactivity of the $\alpha, \beta$-unsaturated esters indicated that other side products are possible. However, other routes to esterification were not conceivable. It is noted that long fluorinated moieties decreased the nucleophilicity of the hydroxyl group but reduces the formation of other side-products. Further considerations would be required to fully understand the reactivity of the $\alpha, \beta$-unsaturated esters in presence of DCC, DMAP and a nucleophile. In addition, thanks to the fluorinated groups, highly hydrophobic polymers were made by UV-curing. An electron acceptor/donor system (maleate/vinyl ether) showed a complete conversion in less than $40 \mathrm{~s}$ for both tested maleate monomers. Further studies will be carried out for the optimization of the photopolymerization kinetics. The choice of photoinitiator, its concentration as well as the influence of the substituent will be investigated.

\section{Conflicts of interest}

There are no conflicts to declare.

\section{Acknowledgements}

This research project has received funding from the European Union's Horizon 2020 research and innovation program under grant agreement No. 690917 - PhotoFluo; Natural Sciences and Engineering Research Council of Canada (NSERC), Discovery Grants Program RGPIN-2015-05513 and Ministère de l'Education supérieure et de la recherche. 


\section{Notes and references}

1 J. P. S. Farinha, J. Wu, M. A. Winnik, R. Farwaha and J. Rademacher, Macromolecules, 2005, 38, 4393-4402.

2 J. V. Crivello and T. M. McGrath, J. Polym. Sci., Part A: Polym. Chem., 2010, 48, 4726-4736.

3 F. R. Mustata and I. G. Bicu, Ind. Eng. Chem. Res., 2008, 47, 1355-1364.

4 H. Lee, J. W. Pack, W. Wang, K. J. Thurecht and S. M. Howdle, Macromolecules, 2010, 43, 2276-2282.

5 J. Wu, J. K. Oh, J. Yang, M. A. Winnik, R. Farwaha and J. Rademacher, Macromolecules, 2003, 36, 8139-8147.

6 E. Di Cola, N. Plucktaveesak, T. A. Waigh, R. H. Colby, J. S. Tan, W. Pyckhout-Hintzen and R. K. Heenan, Macromolecules, 2004, 37, 8457-8465.

7 D. Taura, A. Hashidzume, Y. Okumura and A. Harada, Macromolecules, 2008, 41, 3640-3645.

8 C. Decker, C. Bianchi, D. Decker and F. Morel, Prog. Org. Coat., 2001, 42, 253-256.

9 R. Auvergne, R. Saint-Loup, C. Joly-Duhamel, J. J. Robin and B. Boutevin, J. Polym. Sci., Part A: Polym. Chem., 2007, 45, 1324-1335.

10 L. Pichavant, C. L. Guillermain and X. Coqueret, Biomacromolecules, 2010, 11, 2415-2421.

11 C. Decker and D. Decker, Polymer, 1997, 38, 2229-2237.

12 T. Haraldsson, M. Johansson and A. Hult, J. Polym. Sci., Part A: Polym. Chem., 2010, 48, 2810-2816.

13 C. Y. Huang and A. G. Doyle, J. Am. Chem. Soc., 2015, 137, 5638-5641.

14 N. Kaplaneris, A. Bisticha, G. N. Papadopoulos, D. Limnios and C. G. Kokotos, Green Chem., 2017, 19, 4451-4456.
15 N. Yoshino, M. Morita, A. Ito and M. Abe, J. Fluorine Chem., 1995, 70, 187-191.

16 G. Malinverno, G. Pantini and J. Bootman, Food Chem. Toxicol., 1996, 34, 639-650.

17 C. M. Friesen and B. Améduri, Prog. Polym. Sci., 2018, 81, 238-280.

18 D. W. Smith, S. T. Iacono and S. S. Iyer, Handbook of Fluoropolymer Science and Technology, Wiley, 2014.

19 B. Neises and W. Steglich, Angew. Chem., Int. Ed. Engl., 1978, 17, 522-524.

20 A. Sethi, A. Bhatia, D. Shukla, A. Kumar, R. Sonker, R. Prakash and G. Bhatia, J. Mol. Struct., 2012, 1028, 88-96.

21 X. WAng, Q. Ye, J. Song, C. M. Cho, C. He and J. Xu, RSC Adv., 2015, 5, 4547-4553.

22 E. Baysak, H. Durmaz, U. Tunca and G. Hizal, Macromol. Chem. Phys., 2017, 218, 1600572.

23 U. Gross, P. Koos, M. O'Brien, A. Polyzos and S. V. Ley, Eur. J. Org. Chem., 2014, 2014(29), 6418-6430.

24 P. Nolis, A. Roglans and T. Parella, J. Magn. Reson., 2005, 173, 305-309.

25 T. L. Troyer, H. Muchalski, K. B. Hong and J. N. Johnston, Org. Lett., 2011, 13, 1790-1792.

26 A. Volonterio, C. R. De Arellano and M. Zanda, J. Org. Chem., 2005, 70, 2161-2170.

27 T. Marcelli, F. Olimpieri and A. Volonterio, Org. Biomol. Chem., 2011, 9, 5156-5161.

28 A. Vitale, R. Bongiovanni and B. Ameduri, Chem. Rev., 2015, 115, 8836-8866.

29 A. Vitale, M. Quaglio, S. Marasso, A. Chiodoni, M. Cocuzza and R. Bongiovanni, Langmuir, 2013, 29, 15711-15718. 